\title{
Täsmäviljelyn paikkatietojen käsittelyn ja yhteensopivuuden kehittäminen
}

\author{
Katja Polojärvi $^{1)}$, Mika Luimula ${ }^{2)}$, Pertti Verronen ${ }^{2)}$, Mika Pahkasalo ${ }^{2)}$, Markku Koistinen ${ }^{3)}$ ja Jouni \\ Tervonen $^{4}$ \\ ${ }^{1)}$ Oulun seudun ammattikorkeakoulu, Luonnonvara-alan yksikkö, Metsäkouluntie, 90660 Oulu, \\ katja.polojarvi@oamk.fi \\ ${ }^{2)}$ CENTRIA Tutkimus ja kehitys, RFMedia-laboratorio, Vierimaantie 5, 84100 Ylivieska, \\ etunimi.sukunimi@centria.fi \\ ${ }^{3)}$ MTT, Kasvintuotannon tutkimus, Vakolantie 55, 03400 Vihti, markku.koistinen@mtt.fi \\ ${ }^{4)}$ Oulun Eteläisen instituutti, RFMedia-laboratorio, Oulun yliopisto, Vierimaantie 5, 84100 Ylivieska, \\ jouni.tervonen@oulu.fi
}

\section{Tiivistelmä}

Täsmäviljelyn suunnittelu, toteutus ja arviointi perustuvat paikkatietoihin, joita esimerkiksi työkoneisiin ja maatilaympäristöön sijoitettavat sensorit ja laitteistot keräävät. Laitteistojen kirjo johtaa siihen, että maatilalla tuotettu paikkatieto vaihtelee laadultaan ja on vaikeasti yhdistettävissä toisiinsa. Paikkatiedon tehokas hyödyntäminen viljelyssä edellyttää tietojärjestelmää, jonka avulla viljelijä pystyy yhdistämään maatilan tietoja toisiinsa ja täydentämään niitä ulkopuolisten toimijoiden tuottamilla aineistoilla. Erilaiset tietomallit, -formaatit, rajapinnat ja koordinaattijärjestelmät haastavat tietojen yhteensovittamisen eri laitteistojen, ohjelmistojen ja tietojärjestelmien välillä.

Hajautetut järjestelmäarkkitehtuurit mahdollistavat eri lähteistä peräisin olevan paikkatiedon yhdistämisen. Järjestelmäkehitystyön tavoitteena oli toteuttaa ja demonstroida erilaisten arkkitehtuurija protokollavaihtoehtojen pohjalta tietojärjestelmä, joka vastaa täsmäviljelyjärjestelmien yhteentoimivuuden vaatimuksia. Tietojärjestelmän toteutuksessa sovellettiin paikkatietostandardeja, paikkaperustaisten järjestelmien ja palveluiden alustaa sekä sensoriverkkoteknologiaa. OGC:n (Open Geospatial Consortium) Web Feature Service -rajapinnan (WFS) avulla sensoritietoa välitettiin SQL-tietokantaan langattomasti maanpinnan alta sekä toisen organisaation palvelimelta. Lisäksi järjestelmään välitettiin valmiiksi käsiteltyä ja analysoitua peltotietoa. Taustalla on ajatus viljelijöille suunnattavasta tietopalvelutoiminnasta.

Demonstraatiossa testattiin langattoman sensoriverkkoradion kuuluvuutta maanpinnan alta (syvyys $30 \mathrm{~cm}$ ). Testauksissa signaalin voimakkuus riitti ihanneolosuhteissa muutaman kymmenen metrin päähän. Järjestelmässä maaperän lämpötila- ja kosteustiedot välittyvät langattomasti pääsolmulaitteelle, joka on kytkettynä tietokoneeseen. PC:lle kehitetty sovellus kysyy tietoja pääsolmulaitteelta CENTRIA Protokollaa käyttäen sekä välittää viestin (HTTP POST) WFS:lle käytettävissä olevaa yhteyttä (esim. WLAN, 3G) käyttäen.

MTT:n peltotyökoneiden keräämää vektorimuotoista satotietoa siirrettiin WFS:lle luomalla palvelinyhteys MTT:n palvelimelta. MTT:n täsmäviljelyaineistoja hyödynnettiin myös AgriHandler -sovelluksen kehitystyössä. Tietokannan ylläpitämiseen kehitetyllä sovelluksella tietojen käsittelijä voi ladata tietokantaan maatilaa ja sen peltolohkoja koskevia paikkatietoja kuten lohkorajat ja ravinnetasekartan. Lisäksi kehitettiin aineistojen tarkastelua varten AgriViewer -web-sovellus.

Toteutetun hajautetun järjestelmäarkkitehtuurin toiminnallisuus demonstroitiin ja testattiin. Rajapintojen toteutus täytti järjestelmän yhteentoimivuuden ja skaalautuvuuden vaatimukset. WFSrajapinta soveltui hyvin monimuotoisten vektoriaineistojen välittämiseen. Jatkokehityskohteita ovat paikkatietojen automaattisen käsittelyn ohella rasteriaineistojen ja analyysipalvelujen välittäminen OGC:n WCS- ja WPS-rajapinnoilla.

Asiasanat: täsmäviljely, paikkatieto, yhteentoimivuus, hajautettu järjestelmäarkkitehtuuri 


\section{Johdanto}

Tarkennetussa kasvinviljelyssä eli täsmäviljelyssä viljelytoimenpiteet suunnitellaan, toteutetaan ja arvioidaan paikkatietojen avulla. Tuotanto-olosuhteiden alueellinen ja ajallinen vaihtelu voidaan ottaa huomioon viljelyn suunnittelussa seuraamalla maatilaympäristön olosuhteita sensoriverkkojen avulla. Työkoneisiin asennettavat laitteistot ja ohjelmistot mahdollistavat viljelyn tarkan toteutuksen ja arvioinnin paikkatietoihin perustuen. Täsmäviljelyn tavoitteena oleva tuotannon tehokkuus toteutuu vain, jos sen perustana olevan paikkatiedon laatu ja spatiaalinen tarkkuus ovat riittävät. Jotta paikkatietoja voidaan käyttää maatilalla tehokkaasti päätöksenteon tukena, maatilan sisäisistä ja ulkopuolisista tietolähteistä peräisin olevaa paikkatietoa pitää pystyä yhdistämään ja välittämään eri laitteistojen, ohjelmistojen ja tietojärjestelmien välillä (Steinberger ym. 2008; Nash ym. 2009). Lisäksi tietoa on analysoitava ja muutettava informaatioksi, joka tukee päätöksentekoa (Pesonen ym. 2008).

Tiedonkeruujärjestelmien ja täsmäviljelysovellusten moninaisuus johtaa suureen määrään erilaisia tietoformaatteja ja rajapintoja tehden tiedonhallinnan haastavaksi (Steinberger ym. 2008). Tiedonsiirtoon liittyvien rajoitteiden ja järjestelmien yhteensopimattomuuden lisäksi merkittävä tiedonhallinnallinen ongelma on, ettei maanviljelijöiden aika, tietotekniset taidot tai motivaatio riitä arvioimaan ja käsittelemään täsmäviljelyssä kertynyttä tietoa (Pesonen ym. 2008). Täsmäviljelytietojen käsittelyä varten tarvitaankin ulkopuolisia automatisoituja asiantuntijajärjestelmiä. Tarve erilaisille tietopalveluille sekä yhteistyö useiden toimijoiden kanssa edellyttävät, että paikkatietoa voidaan välittää viljelijän ja sidosryhmien välillä. Tietoformaattien ja koordinaattijärjestelmien muunnosten ja tiedon manuaalisen käsittelyn sijaan tietoa voidaan hallita tehokkaasti paikkatiedoille soveltuvilla tietokantajärjestelmillä ja standardoitujen rajapintojen käytöllä (Yeung \& Hall 2007).

Täsmäviljelyn toimenpiteiden ja prosessien automaatio edellyttää järjestelmää, joka pystyy keräämään tietoa sekä työkoneilta että pellosta. Geosensoriverkot (Geosensor Networks - GSN) tarjoavat nopeasti kehittyvän tekniikan, joka soveltuu myös maatalouden ilmiöiden seurantaan. Geosensoriverkot määritellään sensoriverkoiksi, jotka monitoroivat ilmiöitä maantieteellisessä tilassa (Nittel ym. 2004). Ne edustavat monitieteistä tutkimusalaa, jossa yhdistyy geoinformatiikan, tietojenkäsittelyopin, telekommunikaation ja sensoriteknologian alat.

Paikkatietoiset alustat ovat yksi muoto hajautetuista paikkatietojärjestelmistä (Geographic Information System - GIS). Hajautettu GIS voidaan mär̈rittää verkkokeskeiseksi GIS-työkaluksi, joka langallista tai langatonta verkkoa käyttäen tarjoaa pääsyn hajautettuun tietoon, välittää paikkatietoa ja suorittaa GIS-analyysejä (Chu \& Buyya 2007).

Tällä tutkimusalalla tärkeimmät toimijat ovat olleet Open Geospatial Consortium (OGC) ja Yhdysvaltain avaruusjärjestö NASA. OGC:n standardeista OpenGIS Interface Standard (OGC 2007a) määrittelee avainpalvelut GeoMobility Server -palvelinratkaisuun. Lukuisten palveluiden ohella standardi määrittelee tietokannan kanssa käytettäviä rajapintoja kuten Web Map Server (WMS) ja Web Feature Server (WFS). WMS tuottaa paikkatietoaineistosta dynaamisesti karttoja joko rasterimuodossa tai vektorigrafiikkana. WMS pystyy palvelupyynnöstä generoimaan kartan GML (Geographic Markup Language) -muodossa tallennetusta spatiaalisesta aineistosta. GML on kuvauskieli geometristen kohteiden XML (Extensible Markup Language) -pohjaiseen esittämiseen (Kangasharju \& Tarkoma 2007).

Paikkatiedon sisältäviä geosensoriverkkoja koskien pääosa OGC:n työstä tehdään Sensor Web Enablement (SWE) -työryhmässä, joka tuottaa spesifikaatioita sensoreihin, sensoreiden käyttämiin datamalleihin ja sensoreihin perustuviin Internet-palveluihin liittyen. Tavoitteena SWE-palveluilla on, että sensoreita voidaan käyttää ja ohjata Internet-yhteydellä (Sheth ym. 2008). Sensor Model Language (SensorML) -formaatti on eräs osa SWE-spesifikaatioita. XML-tiedostomuodot ovat tämän infrastruktuurin avainteknologioita sillä kaikki palvelut ja sisältömallit hyödyntävät XML-mallia (Botts ym. 2006). NASA on käyttänyt OGC:n SWE-spesifikaatioita erilaisissa geosensoriverkko- ja sensoreihin perustuvissa Internet-sovelluksissa, joita on hyödynnetty mm. jäätiköiden ja tulivuorten havainnoinnissa (Chien ym. 2007).

Tärkeä täsmäviljelyjärjestelmissä käytetty standardi on ns. ISOBUS- eli ISO 11783-standardi. Vaikka kyseinen standardikokonaisuus lähtökohtaisesti käsitteleekin traktorin ja eri lisälaitteiden muodostaman työkonekokonaisuuden tietoteknisiä ratkaisuja, määrittelee standardin osa kymmenen (ISO 2009) myös maatilan johtamisen tietojärjestelmän (Farm Management Information System FMIS) ja työkoneen tehtävänohjaimen (Task Controller - TC) tiedonsiirtoa siten, että standardin mu- 
kainen tiedostomuoto on XML. Parhaiten yhteentoimivuus taataan käyttämällä aitoa XMLtiedostomuotoa. Kuitenkin ISO 11783 sallii käyttää XML-tiedostomuodon asemasta myös standardoimatonta tiedostomuotoa. Työkoneen sulautetun tietojärjestelmän toteutuksessa onkin toisinaan kustannussyistä tai resurssien (esim. muistikapasiteetti) niukkuudesta johtuen tarvetta tiiviimpään tiedostorakenteeseen. Tällöin aidosta perus-XML:stä johdettujen kompressoitujen tiedostomuotojen (esim. BXML tai SensorML) käytöllä saavutetaan resurssien säästöä ilman yhteentoimivuuden menettämistä.

Järjestelmäkehitystyön tarkoituksena oli demonstroida tietojärjestelmä, joka mahdollistaa täsmäviljelyssä syntyvien paikkatietojen keräämisen, tallentamisen, siirtämisen ja hallinnan. Kehitystyön lähtökohtana on käytetty maatilan johtamisen tietojärjestelmän arkkitehtuuria, joka on suunniteltu pohjoismaisessa InfoXT-projektissa (Pesonen ym. 2008). Kehitystyössä sovellettiin paikkaperustaisten järjestelmien ja palveluiden alustaa ja sensoriverkkoteknologiaa tavoitteena demonstroida järjestelmä, joka yhteentoimivuudeltaan vastaa maatilan johtamisen tiedonhallinnollisia tarpeita.

\section{Järjestelmän kuvaus}

Demonstroitu järjestelmä toteutettiin Locawe-alustalle, joka on CENTRIA Tutkimus ja kehityksen Ylivieskan yksikössä kehitetty ohjelmistoalusta paikkaperustaisille järjestelmille ja palveluille (Luimula ym. 2009, Luimula 2010). Locawe-alusta on suunniteltu sisä- ja ulko-olosuhteisiin. Alusta koostuu mobiiliyksiköistä ja palvelimista, jotka mahdollistavat palvelut esimerkiksi seurannalle ja kommunikaatiolle. Alustalle voidaan toteuttaa käyttöliittymiä, joissa voidaan hyödyntää erilaisia mediaformaatteja sekä sijainti- ja sensoritietoa (Luimula ym. 2010). Alustan aikaisemmissa maanviljelysovelluksissa (Tervonen ym. 2006, Luimula ym. 2009) sensoriverkon solmu- ja mobiililaitteiden välinen kommunikaatio on toteutettu binäärimuodossa OGC:n SensorML- ja BXML-spesifikaatioihin perustuen (OGC 2007b, OGC 2006) (kuva 1).

Hajautetun järjestelmäarkkitehtuurin toteutus on esitetty kuvassa 2. Locawe-palvelimella OGC:n WFS-standardi toimii rajapintana SQL-tietokannan ja sovellusten välillä. WFS-viestit sisältävät sekä XML:n perusmääritykset että suoritettavien toimien määritykset. Tietokantakyselyissä tarvittavat tiedot on toteutettu XML-muodossa sisältäen esimerkiksi GML-tyyppisiä määrityksiä. WFS huolehtii käyttöoikeuksien tunnistamisesta ja määrää siten, millaisia tietokantakyselyjä käyttäjä voi tehdä. WFS hallinnoi SQL-tietokantaa ja oikeaa tietoformaattia. WFS-viestit voivat sisältää kuvia binäärimuodossa sekä vektoritietoa GML-muodossa.

Järjestelmän yhteentoimivuus demonstroitiin välittämällä palvelimelle paikkatietoa eri lähteistä. WFS-rajapinta huolehtii tiedon välityksestä maanpinnan alaisesta sensoriverkosta PC:n toimiessa yhdyskäytävänä. WFS huolehtii myös MTT:n peltotyökoneiden tuottamien tietojen välityksen Locawepalvelimelle MTT:n palvelinten kautta. MTT:n peltotyökoneiden satotietoja hyödynnettiin myös AgriHandler- ja AgriViewer-sovelluksissa.

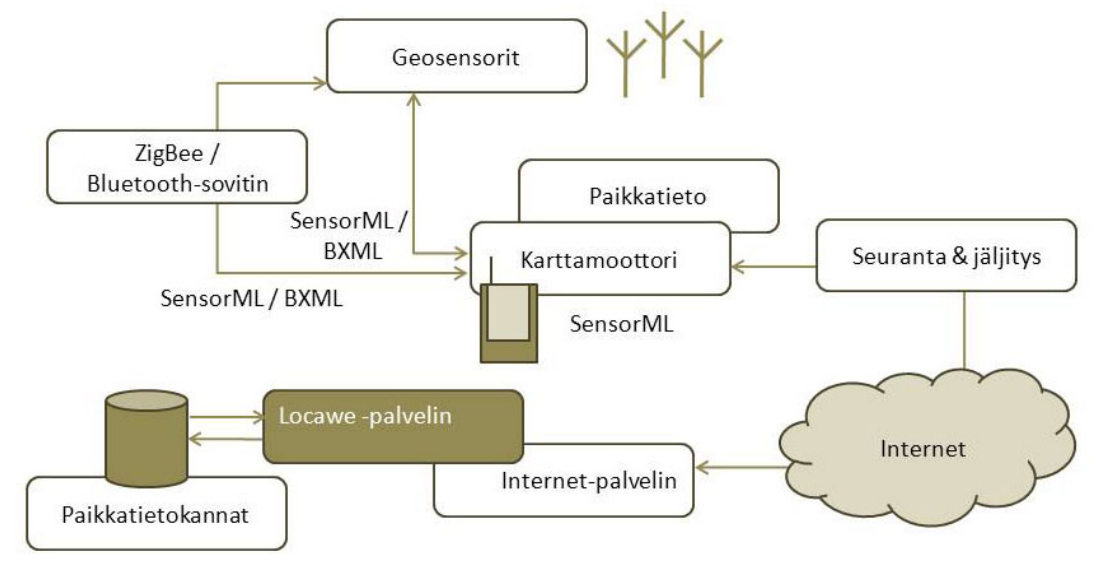

Kuva 1. Geosensoreiden ja mobiililaitteiden käyttö Locawe-alustalla aikaisemmissa tutkimuksissa. 


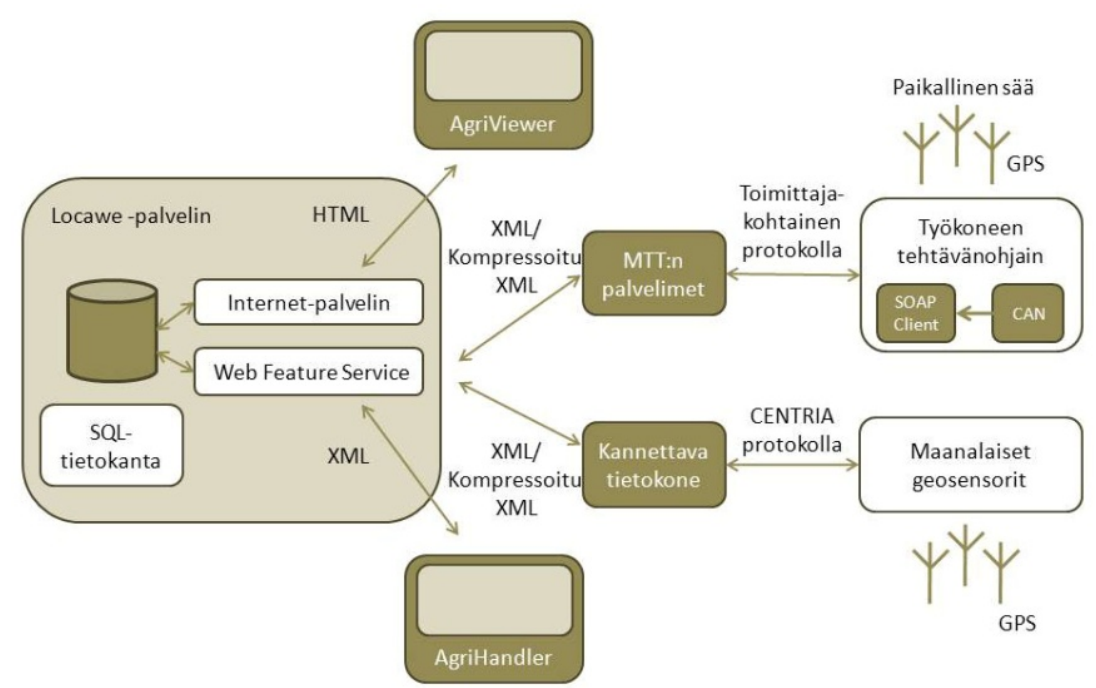

Kuva 2. Täsmäviljelyn sensoritietojen välittäminen eri lähteistä OGC:n WFS-rajapinnan avulla.

\section{Maanalainen sensoriverkko}

Maanalaisen sensoriverkon osalta tavoitteena oli testata signaalin kuuluvuutta ja mittaustiedon välitystä osana tietojärjestelmää, ei niinkään kehittää menetelmiä maaperän ominaisuuksien mittaamiseen. Demonstraatio toteutettiin langattomilla sensoriverkkoradioilla, jotka eivät varsinaisesti ole maaperämittauksiin tarkoitettuja. Maanpinnan alle $30 \mathrm{~cm}: n$ syvyyteen sijoitetut radiolähettimet käyttivät IEEE 802.15.4/ZigBee-standardin mukaista 868 MHz:n taajuuskaistaa 11 dBm:n lähetysteholla. Tiusasen (2009) mukaan kyseinen taajuuskaista soveltuu parhaiten maanpinnan alaiseen maaperämittaukseen. Testimittauksissa signaalin kuuluvuusalue ulottui 28,5 metrin etäisyydelle suotuisissa olosuhteissa maaperän kosteuspitoisuuden ollessa alhainen. Maaperämittauksiin soveltuvilla laitteilla tehdyt pitkäaikaiset mittaukset ovat osoittaneet, että maaperän kosteus vaikuttaa merkittävästi signaalin kuuluvuuteen maanpinnan alta (Tiusanen 2009, Tiusanen 2007).

Demonstroidussa järjestelmässä maaperän lämpötila- ja kosteustiedot välittyvät maanalaisessa sensoriverkossa langattomasti pääsolmulaitteelle, joka on kytkettynä tietokoneeseen. PC:lle kehitetty sovellus kysyy tietoja pääsolmulaitteelta CENTRIA Protokollaa käyttäen, joka on suunniteltu kevyeksi vaihtoehdoksi kommunikoida sensoreiden kanssa. PC-sovellus välittää HTTP POST-viestin WFS:lle käytettävissä olevaa yhteyttä (esim. WLAN, 3G) käyttäen. Käytetyissä sensorilaitteissa ei ole paikannusominaisuutta, mutta järjestelmädemonstraatiota varten kehitetyssä tietokoneohjelmassa käyttäjä voi sijoittaa sensorit pellolle oikeille paikoilleen tai tuoda ohjelmaan GPS-laitteella paikannetut tarkemmat sijaintitiedot.

\section{Käyttöliittymät}

Demonstroitua järjestelmää varten kehitettiin kaksi käyttöliittymää. AgriHandler-sovelluksessa (kuva 3) käyttäjä voi ylläpitää tietokannan maatilaa ja sen peltolohkoja koskevia tietoja WFS-rajapinnan kautta. Tietokannan hallinnointityökalun ohella sovellus toimii myös tietojenkäsittelijän työkaluna alemmilla käyttöoikeuksilla. Sovelluksen tarkoituksena on demonstroida, kuinka valmiiksi käsiteltyä ja analysoitua täsmäviljelytietoa voidaan välittää viljelijälle ulkopuolisena tietopalveluna. Tietojenkäsittelijällä on palvelun tarjoajana mahdollisuus saada tietokannasta asiakasta eli viljelijää koskevia maatila- ja lohkotietoja paikalliseen tiedostoon ja vastaavasti mahdollisuus päivittää analysoitua tietoa tietokantaan. Viestit välittyvät WFS:Ile HTTP POST-viesteinä. Esimerkiksi kasvulohkon ravinnetasekartan lisääminen tietokantaan muodostaa tapahtuman, jolla on oma tietokantataulu. Koordinaattijärjestelmän muuttuessa tietokantaan muodostuu uusi taulu. Tapahtumien periytyminen on otettu huomioon tietokannan suunnittelussa. AgriHandler-sovellusta demonstroitiin MTT:n peltotyökoneiden keräämillä satotiedoilla vektori- (MIF) ja kuvamuotoisena (PNG). Sovelluksella voidaan lisäksi hallinnoida maanalaisen sensoriverkon mittaustietoja. Sovellus tukee tällä hetkellä WGS84- ja ETRSTM35FIN-koordinaattijärjestelmiä. 


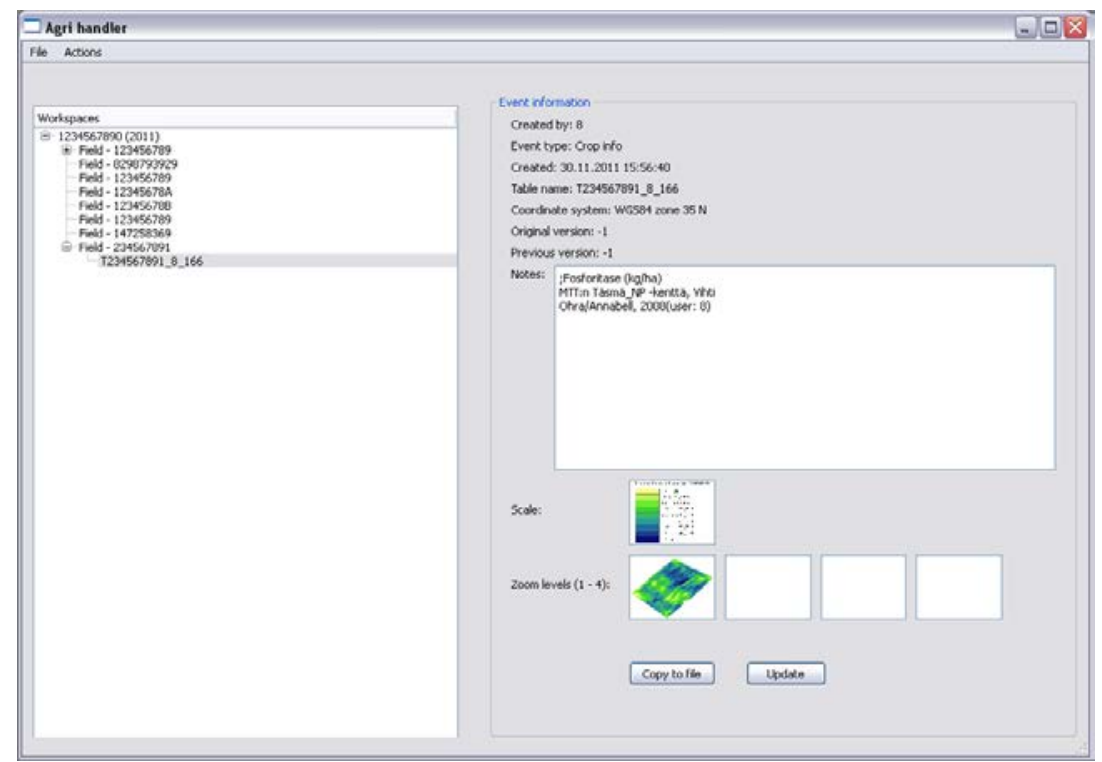

Kuva 3. Tapahtumaa koskevat tiedot AgriHandler-sovelluksessa.

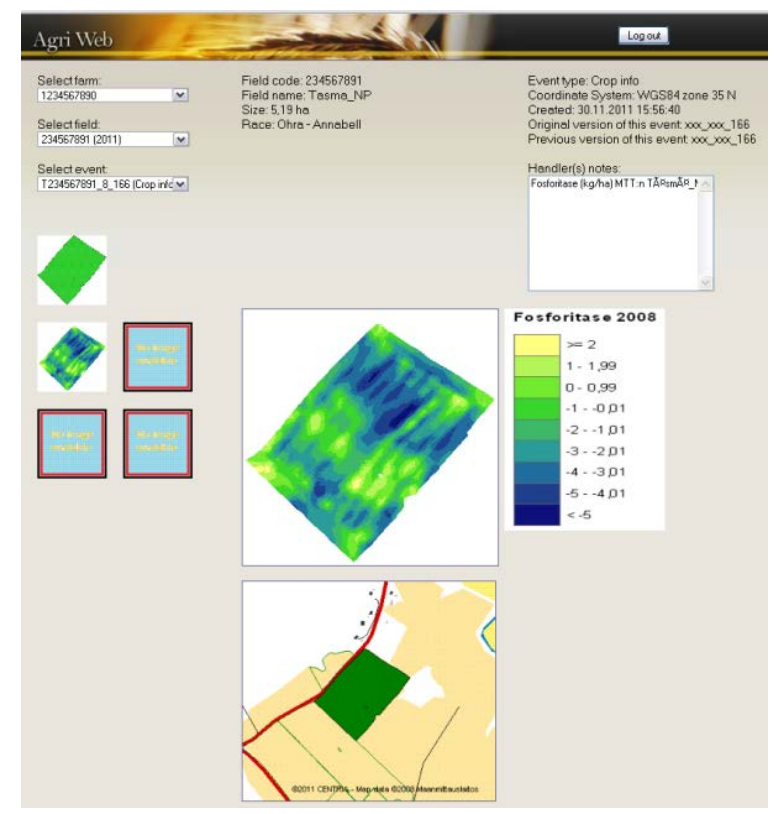

Kuva 4. Tapahtumaa koskevat perustiedot ja analysoidut tiedot AgriViewer -web-selaimessa.

AgriViewer -web-selaimella (kuva 4) loppukäyttäjä voi katsella tietokannan tietoja. WFS-rajapinta huolehtii ainoastaan käyttäjien tunnistuksesta. Käyttäjillä on vain lukuoikeudet.

\section{Työkoneen tehtävänohjain (Task Controller - TC)}

Järjestelmädemonstraatiossa toteutetussa TC-simulaatiossa (kuva 5) keskityttiin erityisesti mobiiliyhteyteen liittyviin haasteisiin. Luotettava mobiilidatayhteys liikkuvien maataloustyökoneiden käyttöympäristössä ei ole itsestäänselvyys. Peltotyöskentelyssä on kuitenkin ensiarvoisen tärkeää, että työntekijä ja tiedonkeruujärjestelmät pystyvät reaaliaikaiseen kahdensuuntaiseen tiedonvaihtoon toimintaa tukevien, mahdollisesti pilvipalveluina tarjottavien, päätöksentekojärjestelmien kanssa.

Mobiilidatayhteyden vaihtelusta ja ajoittain tapahtuvista yhteyskatkoksista johtuen lähetettävän datapaketin koon tulee olla mahdollisimman pieni, jotta tiedonsiirtoa voidaan jatkaa riittävän luotettavasti myös alhaisemmilla yhteysnopeuksilla. Simulaatiossa lähetettävän paketin kooksi valittiin yksi 
rivi kerättyä tietoa per lähetysjakso. Peltoviljelytutkimustyössä tiedonkeruu- ja lähetystaajuudeksi on asetettu viisi otosta sekunnissa mikä on katsottu riittäväksi mm. etämonitorointisovellusten tarpeisiin. Tuotantoympäristössä mobiilidatayhteyden vaihteluun, katkeamiseen ja vasteajan kasvamiseen on varauduttava yhteyden laadun ja yhteysnopeuden jatkuvalla monitoroinnilla ja tiedon paikallisella välivarastoinnilla yhteysongelmien aikana.

Simulaatio toteutettiin sekä 3G-mobiilidatayhteydellä että kiinteällä Internet-yhteydellä. Molemmissa testeissä saavutettiin riittävä tiedonsiirtonopeus mm. etämonitorointi- ja neuvontapalveluiden toteuttamiseksi.

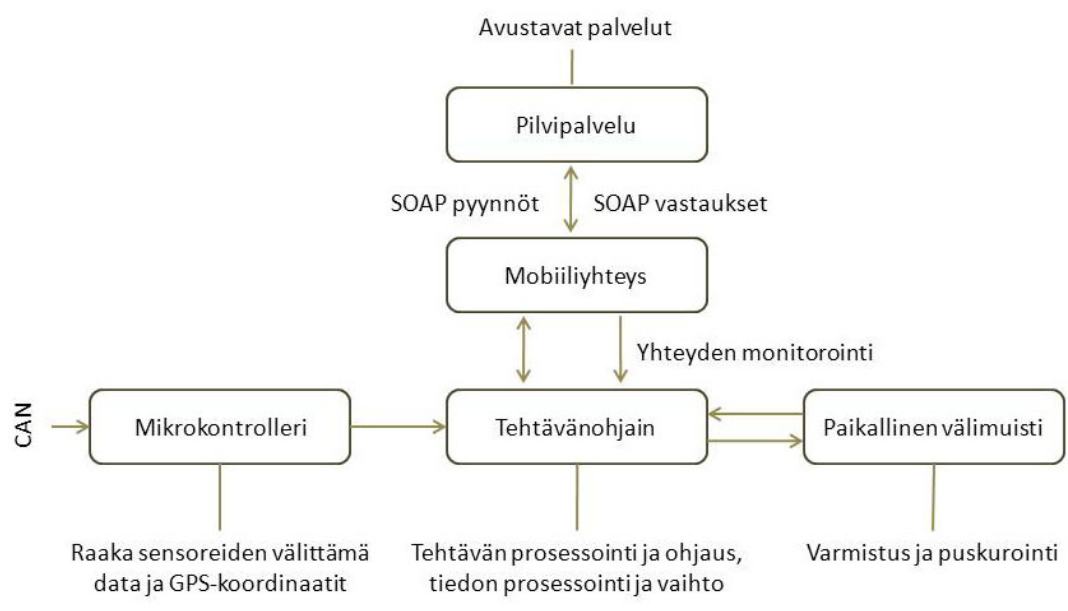

Kuva 5. Keskeiset toimijat mobiilin peltoviljelyn reaaliaikaisessa tiedonkeruussa.

\section{Johtopäätökset}

Hajautetun järjestelmäarkkitehtuurin perustoiminnallisuudet demonstroitiin ja testattiin. Rajapintojen toteutus täytti järjestelmän yhteentoimivuuden ja skaalautuvuuden vaatimukset. Järjestelmässä OGC:n WFS-rajapinta huolehti paikkatiedon välittämisen vektori- ja kuvamuodossa. Jatkossa järjestelmää voidaan kehittää tukemaan rasterimuotoisen aineiston välittämistä OGC:n Web Coverage Service (WCS) -rajapinnalla.

Täsmäviljelyn eri vaiheissa syntyvää raakatietoa täytyy käsitellä ja analysoida ennen kuin sitä voidaan tehokkaasti hyödyntää päätöksenteossa. Jatkossa on tarpeen kehittää menetelmiä tiedonkäsittelyn ja analysoinnin automatisoimiseksi ja edistää siten myös maanviljelijöille suunnattavien tietopalveluiden tarjontaa. Järjestelmäarkkitehtuurin laajentaminen OGC:n Web Processing Service (WPS) -rajapinnalla mahdollistaa paikkatiedon prosessointiin soveltuvien toiminnallisuuksien kuten analyysityökalujen välittämisen järjestelmässä. Muita tietojärjestelmän jatkokehityskohteita ovat tiedonkeruun reaaliaikaisuus sekä käytettävyyden kehittäminen. Käyttäjäkokemusten tutkiminen ja huomioiminen osana järjestelmäkehitystyötä mahdollistaa viljelijöille helppokäyttöisten sovellusten kehittämisen.

\section{Kirjallisuus}

Botts, M. E., Percivall, G., Reed, C. \& Davidson, J. 2006. OGC Sensor Web Enablement: Overview and high level architecture. Proc. of the 2nd International Conference on Geosensor Networks, 175-190.

Chien, S., Tran, D., Davies, A., Johnston, M., Doubleday, J., Castano, R., Scharenbroich, L., Rabideau, G., Cichy, B., Kedar, S., Mandl, D., Frye, S., Song, W., Kyle, P., LaHusen, R. \& Cappaelare, P. 2007. Lights Out Autonomous Operation of an Earth Observing Sensorweb. Proc. of the 7th International Symposium on Reducing the Cost of Spacecraft Ground Systems and Operations (RCSGSO 2007, AIAA).

Chu, X. \& Buyya, R. 2007. Service Oriented Sensor Web. In: N.P. Mahalik (ed.) Sensor Network and Configuration: Fundamentals, Standards, Platforms, and Applications, 51-74. Springer-Verlag, Germany. 
ISO 2009. ISO 11783-10:2009(E), Tractors and machinery for agriculture and forestry - Serial control and communications network - Part 10: Task controller and management information system data interchange. International Organization for Standardization. $101 \mathrm{~s}$.

Kangasharju, J. \& Tarkoma, S. 2007. Benefits of alternate XML serialization formats in scientific computing. Proc. of the 2007 workshop on Service-oriented computing performance: aspects, issues, and approaches, 23-30.

Luimula, M. 2010. Development and Evaluation of the Location-aware Platform. Main Characteristics in Adaptable Location-aware Systems. Väitöskirja, Oulun yliopisto. Acta Universitatis Ouluensis A 551.82 s.

Luimula, M. Sääskilahti, K., Partala, T., Pieskä, S. \& Alaspää, J. 2010. Remote Navigation of a Mobile Robot in a RFID-augmented Environment. Personal and Ubiquitous Computing 14: 125-136.

Luimula, M., Shelby, Z., Markkula, J., Tervonen, J., Weckström, P. \& Verronen, P. 2009. Developing Geosensor Network Support for Locawe Platform - Application of Standards in Low-Rate Communication Context. Proc. of the International Conference on Pervasive Services (ICPS 2009), 73-82.

Nash, E., Korduan, P. \& Bill, R. 2009. Applications of open geospatial web services in precision agriculture: a review. Precision Agric 10: 546-560.

Nittel, S., Stefanidis, A., Cruz, I., Egenhofer, M., Goldin, D., Howard, A., Labrinidis, A., Madden, S., Voisard, A. \& Worboys, M. 2004. Report from the First Workshop on GeoSensor Networks. SIGMOD Record 33(1): 141-144.

OGC 2007a. OpenGIS Geography Markup Language (GML) Endocing Standard, Version 3.2.1, Aug. 2007. Open Geospatial Consortium, Inc.

OGC 2007b. OpenGIS Sensor Model Language (SensorML) Implementation Specification, Version 1.0.0, Jun. 2007. Open Geospatial Consortium, Inc.

OGC 2006. Binary Extensible Markup Language (BXML) Encoding Specification, Version 0.0.8, Jan. 2006. Open Geospatial Consortium, Inc.

Pesonen, L., Koskinen, H. \& Rydberg, A. 2008. InfoXT - User-centric mobile information management in automated plant production. Nordic Innovation Centre, Oslo. $98 \mathrm{~s}$.

Sheth, A., Henson, C. \& Sahoo, S. S. 2008. Semantic sensor web. IEEE Internet Computing12(4): 78-83.

Steinberger, G., Rothmund, M. \& Auernhammer, H. 2008. Mobile farm equipment as a data source in an agricultural service architecture. Computers and electronics in agriculture 65: 238-246.

Tervonen, J., Sorvoja, V., Tikkakoski, M., Hakala, I., Weckström, P., Bialowas, M., Malinen, H. \& Turpeenoja, M. 2006. Control System Utilising Wireless Communication and GPS Position for a Direct Seeding Drill. Proc. of International Conference on Machine Automation (Smart Systems 2006 \& ICMA 2006).

Tiusanen, J. 2009. Wireless Soil Scout prototype radio signal reception compared to the attenuation model. Precision Agric 10: 372-381.

Tiusanen, J. 2007. Validation and results of the Soil Scout signal attenuation model. Biosystems Engineering 97: $11-17$

Yeung, A. K. W. \& Brent Hall, G. 2007. Spatial Database Systems. Springer, Dordrecht. 553 s. 